\title{
Intravenous Fluorouracil versus Oral Capecitabine: Postoperative Chemoradiation for Gastric Cancer
}

\author{
H. Abbas ${ }^{1}$, Shimaa Ahmed1, Ahmed A. S. Salem², Mohamed Abou Elmagd Salem², \\ Mahmoud Hussin ${ }^{2}$, Wessam A. El Sherief ${ }^{3}$ \\ ${ }^{1}$ Department of Radiation Oncology, South Egypt Cancer Institute, Assiut University, Assiut, Egypt \\ ${ }^{2}$ Department of Surgical Oncology, South Egypt Cancer Institute, Assiut University, Assiut, Egypt \\ ${ }^{3}$ Department of Clinical Oncology at Cairo University, Kasr EL Aini School of Medicine, Cairo, Egypt \\ Email: hamza assiut@yahoo.com, shimaa youssif@gmail.com, ${ }^{*}$ ahmed awad721@yahoo.com, \\ salem641972@yahoo.com, mahmud17874@yahoo.com, wessam elsherief@yahoo.com
}

Received 11 August 2015; accepted 5 October 2015; published 8 October 2015

Copyright (C) 2015 by authors and Scientific Research Publishing Inc.

This work is licensed under the Creative Commons Attribution International License (CC BY). http://creativecommons.org/licenses/by/4.0/

\section{(c) (i) Open Access}

\begin{abstract}
Purpose: Aim of this prospective, phase III trial was to compare the efficacy and toxicity of intravenous fluorouracil and oral capecitabine when given concurrently with radiation in adjuvant sitting for adenocarcinoma of the stomach after gastrectomy with D2 resection. Patients and Method: The study included 60 patients having histologically proven adenocarcinoma of the stomach or gastroesophageal junction; stage T2-4 N0-3 M0 after gastrectomy with D2 lymph node dissection. Eligible patients were randomly assigned to receive adjuvant radiotherapy concurrently with intravenous fluorouracil [arm A] or oral capecitabine [arm B]. Results: Ten patients cannot complete their whole treatment course because of either progressive [4 patients; 2 arm A and 2 arm B] or G 3 toxicity [1 patient] or refuse to complete their treatment [5 patients; 3 arm A and 2 arm B]. Patients received fluorouracil have significant increase grade 3 or 4 hematological [neutropenia] and gastrointestinal (diarrhoea, anorexia, and vomiting). During a median follow-up period of 24 months, the 2-year disease free and overall survivals in this study were $60 \%$ and $63.3 \%$, for groups $A$ and $B$ respectively, while overall survival were $63.3 \%$ and $70 \%$ for groups $A$ and $B$ respectively without significant differences. Conclusion: Oral capecitabine concurrently with radiation therapy has comparable efficacy and favourable toxicity profile when compared to infusion fluorouracil as postoperative adjuvant therapy for gastric adenocarcinoma.
\end{abstract}

\section{Keywords}

Fluorouracil, Capecitabine, Chemoradiation, Postoporative, Gastric Cancer

\footnotetext{
*Corresponding author.
}

How to cite this paper: Abbas, H., Ahmed, S., Salem, A.A.S., Salem, M.A.E., Hussin, M. and El Sherief, W.A. (2015) Intravenous Fluorouracil versus Oral Capecitabine: Postoperative Chemoradiation for Gastric Cancer. Journal of Cancer Therapy, 6, 954-962. http://dx.doi.org/10.4236/jct.2015.611103 


\section{Introduction}

Surgery is the curative treatment for gastric cancer. However, the outcome of large T3 - T4 tumours and those with lymph node involvement remains poor after surgical resection alone with high risk of local and distant recurrence [1]. Many studies attempted to improve the prognosis of resected gastric cancers. These include perioperative chemotherapy and postoperative chemotherapy, radiation therapy and chemoradiotherapy [1].

It was a substantial increase in survival with perioperative chemotherapy in the so-called Medical Research Council Adjuvant Gastric Infusional Chemotherapy (MAGIC) study. In this randomized Phase III study of 503 patients, three courses of epirubicin, cisplatinum, and 5-fluorouracil (5-FU) chemotherapy before surgery and three courses afterward significantly prolonged progression-free and overall survival ( $23 \%$ for surgery only and $36 \%$ with perioperative chemotherapy at 5 years). Nevertheless, the MAGIC trial seems to have some weaknesses as $6.1 \%$ of patient had disease progression and became unresectable losing their chance of surgery, $34 \%$ did not received postoperative chemotherapy, and only $42 \%$ completed whole protocol of treatment [2].

Italian Oncology Group for Cancer Research conducted a randomized controlled trial and treated 258 patients with surgery or surgery followed by chemotherapy, with a median follow-up of 72.8 months, there was no significant difference in disease-free survival or overall survival between the two arms [3].

Postoperative radiotherapy alone has no advantage [4], however addition of chemotherapy to postoperative radiotherapy improves survival. The landmark randomized Intergroup 0116 study concluded that postoperative chemoradiotherapy with 5-FU prolonged 5-year overall survival compared to surgery alone (40\% versus $22 \%$ ) [5]. Update of this trial confirms this improvement of survival with more than 10 years median follow-up [6]. In this study chemotherapy was given concurrently only during the first 4 and last 3 days, to a total of 7 days, of radiotherapy, resulting in a limited interaction between both treatment modalities. However in this trial toxicity was relatively high and only $64 \%$ complete chemoradiation course [5].

In patients with advanced gastric cancer, some studies reported that 5-FU-based regimens is effective [7], however many studies found that continuous infusion 5-FU is more effective than the bolus 5-FU gastrointestinal malignancies [8].

Capecitabine is at least as effective and has a favourable side-effect profile compared with 5-FU [9]. In addition, chemoradiotherapy with daily capecitabine is feasible in postoperative patients with gastroesophageal junction and gastric cancer [10].

The ease of oral administration, equivalent efficacy, and inferior toxicity of capecitabine compared with the continuous infusion of 5-FU makes the use of capecitabine concurrently with radiotherapy is an attractive option.

This is phase III study to compare the efficacy and toxicity of intravenous fluorouracil and oral capecitabine when given concurrently with radiation in adjuvant sitting for adenocarcinoma of the stomach after surgery.

\section{Patients and Methods}

The current randomized prospective phase III study included 60 patients with cancer stomach after gastrectomy and was carried out at surgical oncology and radiation oncology departments, South Egypt Cancer Institute, Assiut University and Kasr Al-Einy Cancer Center, Cairo University, during the period from Feb 2008 to Oct 2013. Every patient who participated in this study gave informed consent, and our ethical committee approved the study.

\subsection{Inclusion Criteria}

The study included patients having histologically proven adenocarcinoma of the stomach or gastroesophageal junction in American Joint Committee on Cancer Stage T2-4 N0-3 M0. All patients underwent gastric resection with D2 lymph node dissection with negative pathological tumor margin (R0) with the following eligibility criteria: age $\geq 18$ and $\leq 70$ years; PS $\leq 2$ according to ECOG. Laboratory, they should had a hemoglobin level $\geq 10$ $\mathrm{gm} / \mathrm{L}$, neutrophils $\geq 1.5 \times 10^{9} / \mathrm{L}$ and thrombocytes $\geq 100 \times 10^{9} / \mathrm{L}$, creatinine $\leq 1.25$ ULN (upper limit of normal) and creatinine clearance $\geq 60 \mathrm{ml} / \mathrm{min}$, bilirubin level $\leq 1.5$ ULN and ALP, AST and ALT levels $\leq 3$ ULN.

The surgical requirement for eligibility was curative, with en bloc resection of the tumour with disease-negative margins. All patients had undergone extensive (D2) lymph node dissection. This procedure entails resection of all perigastric lymph nodes and celiac, splenic or splenic-hilar, hepatic arterial, and cardial lymph nodes, de- 
pending on the location of the primary tumor.

We excluded patients with previous malignancies or co morbidity that might compromise delivery of the planned treatment.

Treatment must start within 45 days after surgery.

Eligible patients were randomly assigned to receive adjuvant radiotherapy concurrently with intravenous fluorouracil [arm A] or oral capecitabine [arm B]. Stratification factors were disease stage, type of surgery (subtotal $\mathrm{v}$ total gastrectomy) and availability of capecitabine.

\subsection{Treatment Plan}

\section{Surgery}

Twenty-five patients (41.7\%) underwent subtotal distal gastrectomy as the tumors were located in antrum while twelve patients (20\%) underwnt subtotal proximal gastrectomy while Thirteen patents (38.3\%) underwnt total gastrectomy. In all patients, a D2 lymphadenectomy was performed.

\subsection{Chmeotherapy}

\subsubsection{Arm A}

One cycle of chemotherapy (fluorouracil, $425 \mathrm{mg} / \mathrm{m}^{2} /$ day, and leucovorin, $20 \mathrm{mg} / \mathrm{m}^{2} /$ day, for 5 days). On day 28 , chemoradiotherapy started with fluorouracil $\left(400 \mathrm{mg} / \mathrm{m}^{2} /\right.$ day $)$ and leucovorin $\left(20 \mathrm{mg} / \mathrm{m}^{2} /\right.$ day $)$ on the first four and the last three days of radiotherapy were given. Additional two cycles of chemotherapy (fluorouracil, 425 $\mathrm{mg} / \mathrm{m}^{2} /$ day, and leucovorin, $20 \mathrm{mg} / \mathrm{m}^{2} /$ day, for 5 days), started one month after radiotherapy.

\subsubsection{Arm B}

Patient received one cycle of capecitabine $1000 \mathrm{mg} / \mathrm{m}^{2}$ every 12 hours daily for 2 weeks then one week rest (Days 15 - 21).

Chemoradiotherapy started on Day 22, with capecitabine $\left(825 \mathrm{mg} / \mathrm{m}^{2}\right.$ orally every 12 hours after meal, with the first dose administered within 3 hours before radiotherapy), Capecitabine were given on radiation therapy days only.

Additional three cycles of chemotherapy 3 cycles of oral capecitabine $1000 \mathrm{mg} / \mathrm{m}^{2}$ every 12 hours for 2 weeks repeated every 3 weeks, started one month after radiotherapy.

\subsubsection{Radiation Therapy}

The recommended radiation dose was $45 \mathrm{~Gy} / 25$ fractions in 5 weeks.

The patient was simulated and treated with an empty stomach (minimum 4 hours). On simulator, patients immobilized in supine position with arms extended over the head to allow treatment of oblique or lateral fields.

We used fluoroscopic simulation as we can evaluate magnetite of respiratory movement of the left hemidiaphragm to create PTV for GEJ and proximal stomach tumors.

Then patient referred to CT simulator. On the same position of simulation, multiple CT cuts at $0.5 \mathrm{~cm}$ interval throughout the treatment volume (using CT simulator). CT data transferred to the compute treatment planning system. At each CT slice, we defined the target volume, and OAR.

CTV include includes the tumor bed, primary lymph nodes, a minimum $1 \mathrm{~cm}$ expansion of the CTV to create a PTV is appropriate during 3-D treatment planning. We consider greater expansion for target along the left hemidiaphragm to accommodate respiratory movement as determined during flouroscopy. We used data collected from the preoperative upper GI series; CT scan, operative findings, and clip placement define the tumor bed and lymph node areas.

The tumor bed includes the maximum preoperative stomach volume. Caese with T3 or T4 tumors, we included areas of local tumor extension and the medial two thirds to three fourths of the left hemidiaphragm.

The regional-lymph-node areas that irradiated were Perigastric, celiac, local paraaortic, splenic, hepatoduodenal or hepatic-portal, and pancreaticoduodenal lymph nodes according to the definitions of the Japanese Research Society for Gastric Cancer.

Three-dimensional plan was generated applying ICRU 50 recommendations, the dose to a given volume of kidney or liver must not exceeds its functional tolerance. 


\subsubsection{Follow Up}

During treatment, laboratory investigations [complete blood picture, liver and renal function] every 4 weeks. Patients underwent physical examination to determine GIT toxicities (diarrhea, nausea, vomiting, and mucositis), neurotoxicity, weight loss, fatigue, and hand foot syndrome according to common toxicity criteria of National Cancer Institute version 3.0.

The sites of relapse were classified as follows: the relapse was coded as: Locoregional (tumor detected within the radiation fields), peritoneal (tumor detected in the peritoneal cavity) and distant metastases (metastases were outside the peritoneal cavity, including liver).

\subsubsection{Statistical Considerations}

The primary end point of the study was disease-free survival (DFS), with overall survival, recurrence rate, and toxicity as key secondary end points.

All $P$ values are two sided.

\section{Result}

Between Feb 2008 and Oct. 2013, a total of 60 patients attended to South Egypt Cancer Institute, Assiut University and Kasr Al-Einy Cancer Center, Cairo University were entered in this study.

\subsection{Patients' Characteristics}

This study included 60 patients (36 males and 26 females) with ages ranging from 24 to 62 years. Most of our patients (95\%) had performance status 0 or 1 . Twenty-five patients $(41.7 \%)$ underwent subtotal distal gastrectomy as the tumors were located in antrum while twelve patients (20\%) underwnt subtotal proximal gastrectomy while Thirteen patents (38.3\%) underwnt total gastrectomy. In all patients, a D2 lymphadenectomy was performed. The patients were at high risk for relapse; forty-six patients had pathologically involved nodes; 31 (51.7\%) N1 nodes, 15 (25\%) N2 nodes and 14 (23.3\%) N0 nodes and 68.3\% had stage T3 or T4 (Table 1).

\subsection{Treatment Delivery}

Eighty per cent of group A and 86.7 group B completed their whole treatment course either due to doctor withdrawal [one patient] as of intolerability for treatment, disease progression [4 patients and change their line of treatment to platinum based chemotherapy] or patient refusal of treatment due to toxicities [5 patients] as shown in Table 2.

\begin{tabular}{|c|c|c|c|c|}
\hline \multirow{2}{*}{\multicolumn{2}{|c|}{$\begin{array}{c}\text { Variable } \\
\text { Age }\end{array}$}} & A & B & \multirow{2}{*}{$\mathrm{P}$ value } \\
\hline & & 50 & 49 & \\
\hline \multirow{2}{*}{ Sex } & Male & 17 & 19 & \multirow{2}{*}{ NS } \\
\hline & Female & 13 & 11 & \\
\hline \multirow{3}{*}{ PS } & 0 & 7 & 3 & \multirow{3}{*}{ NS } \\
\hline & 1 & 22 & 25 & \\
\hline & 2 & 1 & 2 & \\
\hline \multirow{3}{*}{ Tumour } & $\mathrm{T} 2$ & 10 & 9 & \multirow{3}{*}{ NS } \\
\hline & T3 & 14 & 15 & \\
\hline & $\mathrm{T} 4$ & 6 & 6 & \\
\hline \multirow{3}{*}{ Node } & No & 7 & 6 & \multirow{3}{*}{ NS } \\
\hline & N1 & 16 & 15 & \\
\hline & N2 & 7 & 9 & \\
\hline \multirow{2}{*}{ Gastrectomy } & Total & 11 & 12 & \multirow{2}{*}{ NS } \\
\hline & Partial & 19 & 18 & \\
\hline
\end{tabular}




\subsubsection{Toxicity}

Toxicities of grade 3 or 4 are summarized in Table 3 .

Fluorouracil have significant increase grade 3 or 4 hematological [neutropenia] and gastrointestinal (diarrhoea, anorexia, and vomiting).

\subsubsection{Survival and Relapse}

During a median follow-up period of 24 months, the 2-year disease free and overall survivals in this study were $60 \%$ and $63.3 \%$, for groups $\mathrm{A}$ and $\mathrm{B}$ respectively, while overall survival were $63.3 \%$ and $70 \%$ for groups A and B respectively (Figure 1).

Pattern of relapsed are presented in Table 3, locoregional relapse within radiation field were detected in 20\% of cases while distant metastasis were detected in $18.3 \%$ (Table 4).

Table 2. Treatment delivery.

\begin{tabular}{|c|c|c|c|c|c|}
\hline & \multirow{2}{*}{\multicolumn{2}{|c|}{ Treatment }} & A & B & Total \\
\hline & & & No. [\%] & No. [\%] & No. [\%] \\
\hline & \multirow[t]{2}{*}{ Completed } & & $24[80]$ & 26 [86.7] & 50 [83.3] \\
\hline \multirow{5}{*}{ Not completed } & & Toxicity & $1[3.3]$ & $0[0]$ & $1[1.6]$ \\
\hline & Stop treatment & Refused & $3[10]$ & $2[6.7]$ & 5 [8.3] \\
\hline & & Total & $4[13.3]$ & $2[6.7]$ & 6 [10\%] \\
\hline & \multicolumn{2}{|c|}{ Disease progression } & 2 [6.7] & 2 [6.7] & $4[6.7]$ \\
\hline & \multicolumn{2}{|c|}{ Total } & $6[20]$ & 4 [13.3] & $10[16.6]$ \\
\hline
\end{tabular}

Table 3. Toxicities.

\begin{tabular}{|c|c|c|c|c|}
\hline \multirow{2}{*}{\multicolumn{2}{|c|}{ Toxicity }} & \multicolumn{2}{|c|}{$\geq \mathrm{G} 3$} & \multirow{2}{*}{$P$ value } \\
\hline & & A & B & \\
\hline \multirow{3}{*}{$\begin{array}{l}\text { Hematological } \\
\text { toxicities }\end{array}$} & Anemia & 4 [13.3] & $2[6.7]$ & NS \\
\hline & Neutropenia & $8[26.7]$ & $1[3.3]$ & 0.03 \\
\hline & Thrombocytopenia & $0[0]$ & $0[0]$ & NS \\
\hline \multirow{6}{*}{ GIT toxicities } & Diarrhea & $7[23.3]$ & $0[0]$ & 0.01 \\
\hline & Anorexia & $6[20]$ & $0[0]$ & 0.02 \\
\hline & Nausea & $2[6.7]$ & $0[0]$ & NS \\
\hline & Vomiting & $0[0]$ & $1[3.3]$ & NS \\
\hline & Dysphagia & $2[6.7]$ & $0[0]$ & NS \\
\hline & Mucositis & $6[20]$ & $0[0]$ & 0.03 \\
\hline \multicolumn{2}{|c|}{ Neurotoxicity } & $0[0]$ & $0[0]$ & NS \\
\hline \multicolumn{2}{|c|}{ Weight loss } & $1[3.3]$ & $0[0]$ & NS \\
\hline \multicolumn{2}{|c|}{ Fatigue } & $2[6.7]$ & $0[0]$ & NS \\
\hline \multicolumn{2}{|c|}{ Hand foot syndrome } & $0[0]$ & $0[0]$ & NS \\
\hline
\end{tabular}

Table 4. Pattern of relapse.

\begin{tabular}{cccc}
\hline Site & A & B & P value \\
\hline Local & $5[16.7]$ & $4[13.3]$ & \\
Regional & $2[6.7]$ & $1[3.3]$ & NS \\
Peritoneal & $4[13.3]$ & $6[20]$ & \\
DM & $5[16.7]$ & $6[20]$ & \\
\hline
\end{tabular}




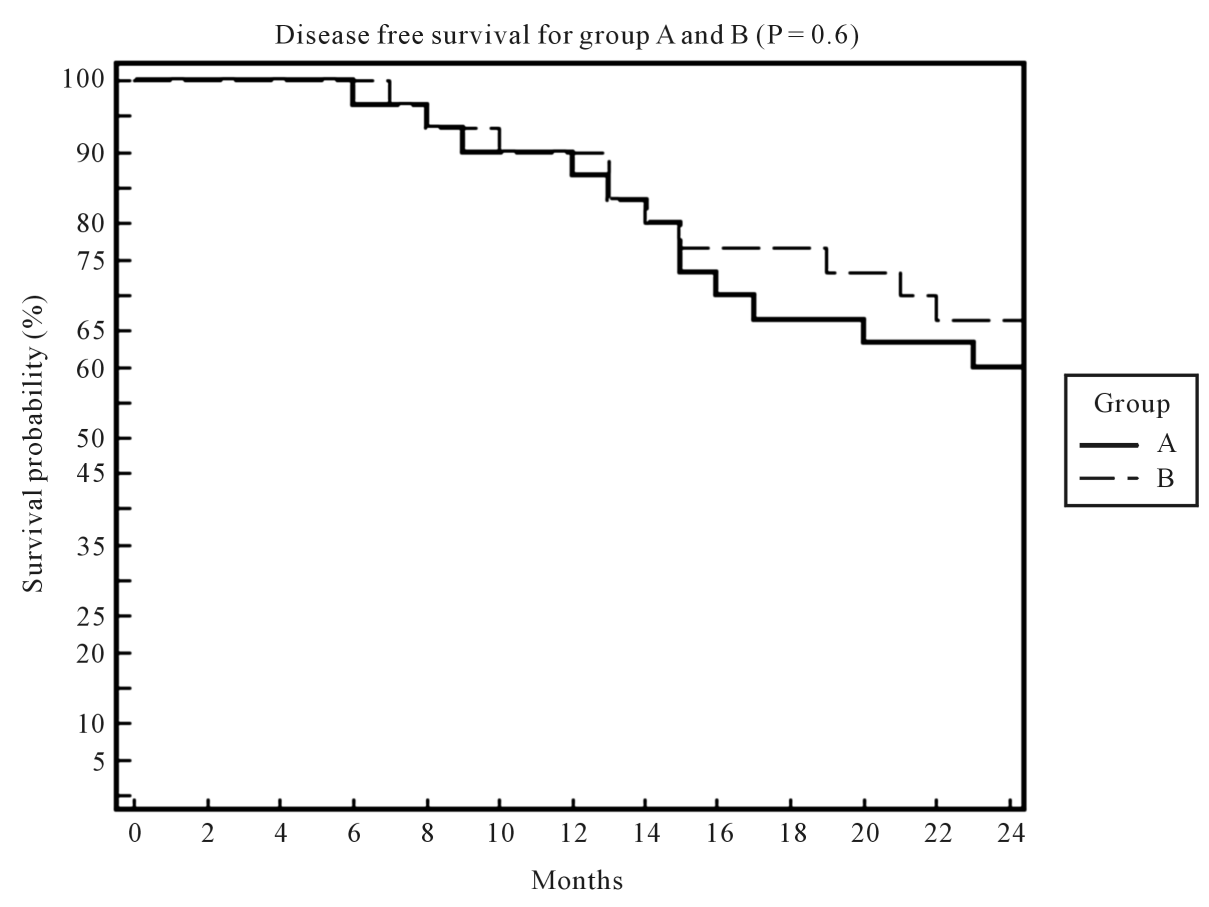

Figure 1. 2-year disease free survival and overall survival.

\section{Discussion}

The landmark trial of the adjuvant therapy of cancer stomach is the intergroup trial SWOG 9008/INT-0116 [5]. Patients with T3, T4, and/or node positive adenocarcinoma of the stomach or GE junction were eligible for participation. After a resection with negative margins, 603 patients were randomized to either observation alone or postoperative combined modality treatment consisting of five monthly cycles of bolus chemotherapy (5-fluorouracil and leucovorin) with RT (45 Gy) concurrent with cycles 2 and 3. There was a significant decrease in local failure as the first site of failure $(19 \%$ vs. $29 \%$ ) as well as an increase in median survival (36 vs. 27 months), 3-year relapse-free survival ( $48 \%$ vs. $31 \%)$, and overall survival $(50 \%$ vs. $41 \%$, $\mathrm{P}=0.005)$ with combined modality treatment. Update of their results with more than 10 years median follow-up, survival remains improved in stage IB-IV (M0) gastric cancer cases treated with post-operative chemoradiation [6].

The Intergroup trial seems to have some weaknesses. First, it was difficult to assess precisely the treatment outcomes as only 181 out of 281 patients (64\%) completed treatment as planned mostly due to increased toxicities (17\%) or refuse to complete their treatment course (8\%). In-addition the limited patients number who underwent D2 dissection in control arm that could explain the higher rate of local recurrence within control group (29\% versus $19 \%)$.

Continuous infusion 5-FU was found to be more effective than the bolus 5-FU gastrointestinal malignancies [8] Capecitabine (Xeloda), an oral fluoropyrimidine, is oral prodrug of 5-FU and absorbed intact through the gut and then activated by a series of enzymatic alterations [11] it is a reasonable alternative 5-FU in particularly when continuous-infusion 5-FU is considered.

In patients with metastatic colorectal cancer, capecitabine was shown to be at least as effective and have a favorable side-effect profile compared with intravenous 5-FU [9].

In patients with advanced gastric cancer, 5-FU-based regimens were reported to be effective [7]. Capecitabine was shown to have equivalent efficacy to continuous-infusional 5-fluorouracil (5-FU) in several phase III for gastric carcinoma [12].

The combination of 5-FU and concurrent radiotherapy was studied extensively in patients with rectal cancer [13]. Furthermore, daily administration of 5-FU analogues has become much easier with the introduction of the oral fluoropyrimidines, such as capecitabine.

The ease of oral administration, equivalent efficacy, and inferior toxicity of capecitabine compared with the continuous infusion of 5-FU makes the use of capecitabine concurrent with radiotherapy an attractive option. 
Capecitabine concurrent with radiotherapy was feasible with manageable toxicities and capable of inducing relevant tumor responses in upper gastrointestinal and rectal cancer [14].

Several phase I studies have already explored the addition of capecitabine with concurrent radiation in adjuvant stomach cancer and shown it to be safe and tolerable [10] [15]. A retrospective study on postoperative adjuvant gastric therapy showed an equivalent survival between capecitabine and 5-FU when concurrent with radiation. They concluded that capecitabine with concurrent radiation could be a reasonable alternative to 5FU-RT as adjuvant treatment in resected stomach cancer [16].

Extended node dissection (D2) was mandatory in our study based on three reasons. Firstly, Japanese investigators emphasis that extended node dissection D2 or more improve survival [17]. Secondly, we preferred to avoid the problem of surgery present in INT-0166 trail. Thirdly, postoperative concurrent chemoradiation after extended node dissection has acceptable toxicity. Lim and his colleagues [18] conducted a trail to evaluate the effect of adjuvant chemoradiation after extended node dissection using the same protocol used in INT-0166 trial. They reported a low rate of local and regional recurrences and concluded that postoperative concurrent chemoradiation has acceptable toxicity and has a potential effect on reducing locoregional recurrence. In addition, an analysis was done in South Korea [19] and evaluated the potential role of postoperative chemoradiation [INT 0166 protocol] after D2, revealed improvement of both recurrence free survival (RFS) and overall survival (OS).

In the present study, locoregional recurrences at irradiation field occurred in $20 \%$ which in comparable with that reported by Lee and his colleagues [15]. MacDonald and his colleagues [5] reported a higher incidence of locoregional recurrence (19\% local and 65\% regional) this difference explained by two reasons. Firstly, only $10 \%$ of patients underwent extensive nodal dissection in addition to the different in of the patter of failure particularly regional failure. Secondly, the differences in the definition of locoregional relapse as we defined it as any recurrence detected within the radiation fields, however in INT-0166 trail; the coded the relapse as local if tumor was detected in the surgical anastomosis, residual stomach, or gastric bed. However, they defined recurrence regional if tumor detected in the peritoneal cavity (including the liver, intraabdominal lymph nodes, and peritoneum). Peritoneal recurrence was the most frequent (55.5\%) pattern of relapse that in agreement with Yoo and his colleagues who reported that peritoneal recurrence was the most frequent (46\%) in gastric cancer patients receiving D2 lymph node dissection [20].

In Japan, they reported 5-year survivals of $46 \%-68 \%$ in patients with D2-3 resected gastric cancer that is comparable to our results [21].

Two-year DFS and OAS was $61.7 \%$ and $66.7 \%$ among our patient that is in agreement with other results compared with the results from postoperative chemoradiotherapy with D2 lymph node dissection study for gastric cancer done by park and his colleagues [22].

Oral capecitabine concurrently with radiation therapy as adjuvant postoperative therapy is tolerable as most of complication with mild degree. Grade 3 or 4 toxicity is reported only in $13.3 \%$ which is significantly lower than reported with fluorouracil this difference explained by the safety profile capecitabine in comparable to 5-FU [1].

Fluorouracil has significantly higher grade 3 toxicities regarded neutropenia, diarrhoea, anorexia and mucosities when compared to capecitabine that confirm the safety profile of capecitabine that is comparable to that reported in other study [23].

83.3\% of patient completed their treatment course, while $16.7 \%$ did not completed their treatment. Their more toxicity reported in arm A [13.3\%], than arm B [6.7\%] which confirm the relative safety profile of capecitabine in comparison with 5-FU when used concurrently with radiation as postoperative adjuvant therapy for gastric adenocarcinoma.

Limitations of the present study were small number of patients and limited follow up period.

In spite of above limitations, we can conclude that oral capecitabine concurrently with radiation therapy has comparable efficacy and favourable toxicity profile when compared to infusion fluorouracil as postoperative adjuvant therapy for gastric adenocarcinoma.

\section{Competing Interests}

No competing interests.

\section{References}

[1] Tham, C.K., Choo, S.P., Poon, D.Y.H., Toh, H.C., Ong, S.Y.K., Tan, S.H., Wang, M.L.C. and Foo, K.F. (2010) Cape- 
citabine with Radiation is an Effective Adjuvant Therapy in Gastric Cancers. World Journal of Gastroenterology, 16, 3709-3715. http://dx.doi.org/10.3748/wjg.v16.i29.3709

[2] Cunningham, D., Allum, W.H., Stenning, S.P., et al. (2006) Perioperative Chemotherapy versus Surgery Alone for Resectable Gastroesophageal Cancer. The New England Journal of Medicine, 355, 11-20. http://dx.doi.org/10.1056/NEJMoa055531

[3] Bajetta, E., Buzzoni, R., Mariani, L., Beretta, E., Bozzetti, F., Bordogna, G., Aitini, E., Fava, S., Schieppati, G., Pinotti, G., Visini, M., Ianniello, G. and Di, B.M. (2002) Adjuvant Chemotherapy in Gastric Cancer: 5-Year Results of a Randomised Study by the Italian Trials in Medical Oncology (ITMO) Group. Annals of Oncology, 13, 299-307. http://dx.doi.org/10.1093/annonc/mdf040

[4] Allum, W.H., Hallissey, M.T., Ward, L.C. and Hocke, M.S., British Stomach Cancer Group (1989) A Controlled, Prospective, Randomised Trial of Adjuvant Chemotherapy or Radiotherapy in Resectable Gastric Cancer: Interim Report. British Journal of Cancer, 60, 739-744. http://dx.doi.org/10.1038/bjc.1989.350

[5] Macdonald, J.S., Smalley, S.R., Benedetti, J., et al. (2001) Chemoradiotherapy after Surgery Compared with Surgery alone for Adenocarcinoma of the Stomach or Gastroesophageal Junction. The New England Journal of Medicine, 345, 725-730. http://dx.doi.org/10.1056/NEJMoa010187

[6] Macdonald, J.S., Benedetti, J., Smalley, S., et al. (2009) Chemoradiation of Resected Gastric Cancer: A 10-Year Follow up of the Phase III Trial INT 0116 (SWOG 9008). Journal of Clinical Oncology, 27, 15s. (Suppl; abstr 4515).

[7] Wagner, A.D., Grothe, W., Haerting, J., et al. (2006) Chemotherapy in Advanced Gastric Cancer: A Systematic Review and Meta-Analysis Based on Aggregate Data. Journal of Clinical Oncology, 24, 2903-2909. http://dx.doi.org/10.1200/JCO.2005.05.0245

[8] Meyerhardt, J.A. and Mayer, R.J. (2005) Systemic Therapy for Colorectal Cancer. The New England Journal of Medicine, 352, 476-487. http://dx.doi.org/10.1056/NEJMra040958

[9] Cunningham, D., Rao, S., Starling, N., et al. (2006) Randomised Multicentre Phase III Study Comparing Capecitabine with Fluorouracil and Xaliplatin with Cisplatin in Patients with Advanced Oesophagogastric Cancer: The REAL 2 Trial. Journal of Clinical Oncology, 24, 18S.

[10] Jansen, E.P., Boot, H., Saunders, M.P., Crosby, T.D., Dubbelman, R., Bartelink, H., Verheij, M. and Cats, A. (2007) A Phase I-II Study of Postoperative Capecitabine-Based Chemoradiotherapy in Gastric Cancer. International Journal of Radiation Oncology, Biology, Physics, 69, 1424-1428. http://dx.doi.org/10.1016/j.ijrobp.2007.05.004

[11] Schuller, J., Cassidy, J., Dumont, E., Roos, B., Durston, S., Banken, L., Utoh, M., Mori, K., Weidekamm, E. and Reigner, B. (2000) Preferential Activation of Capecitabine in Tumor Following Oral Administration to Colorectal Cancer Patients. Cancer Chemotherapy and Pharmacology, 45, 291-297. http://dx.doi.org/10.1007/s002800050043

[12] Kang, Y.K., Kang, W.K., Shin, D.B., Chen, J., Xiong, J., Wang, J., Lichinitser, M., Guan, Z., Khasanov, R., Zheng, L., Philco-Salas, M., Suarez, T., Santamaria, J., Forster, G. and McCloud, P.I. (2009) Capecitabine/Cisplatin versus 5Fluorouracil/Cisplatin as First-Line Therapy in Patients with Advanced Gastric Cancer: A Randomized Phase III Noninferiority Trial. Annals of Oncology, 20, 666-673. http://dx.doi.org/10.1093/annonc/mdn717

[13] Bosset, J.F., Collette, L., Calais, G., et al. (2006) Chemotherapy with Preoperative Radiotherapy in Rectal Cancer. New England Journal of Medicine, 355, 1114-1123. http://dx.doi.org/10.1056/NEJMoa060829

[14] Rodel, C., Grabenbauer, G.G., Papadopoulos, T., et al. (2003) Phase I/II Trial of Capecitabine, Oxaliplatin, and Radiation for Rectal Cancer. Journal of Clinical Oncology, 21, 3098-3104. http://dx.doi.org/10.1200/JCO.2003.02.505

[15] Lee, H.S., Choi, Y., Hur, W.J., Kim, H.J., Kwon, H.C., Kim, S.H., Kim, J.S., Lee, J.H., Jung, G.J. and Kim, M.C. (2006) Pilot Study of Postoperative Adjuvant Chemoradiation for Advanced Gastric Cancer: Adjuvant 5-FU/Cisplatin and Chemoradiation with Capecitabine. World Journal of Gastroenterology, 12, 603-607.

[16] Tham, C.K., Choo, S.P., Poon, D.Y., Toh, H.C., Ong, S.Y., Tan, S.H., et al. (2010) Capecitabine with Radiation Is an Effective Adjuvant Therapy in Gastric Cancers. World Journal of Gastroenterology, 16, 3709-3715. http://dx.doi.org/10.3748/wjg.v16.i29.3709

[17] Hartgrink, H.H., van de Velde, C.J., Putter, H., et al. (2004) Extended Lymph Node Dissection for Gastric Cancer: Who May Benefit? Final Results of the Randomized Dutch Gastric Cancer Group Trial. Journal of Clinical Oncology, 22, 2069-2077. http://dx.doi.org/10.1200/JCO.2004.08.026

[18] Lim, D.H., Kim, D.Y., Kang, M.K., Kim, Y.I., Kang, W.K., Park, C.K., Kim, S., Noh, J.H., Joh, J.W., Choi, S.H., Sohn, T.S., Heo, J.S., Park, C.H., Park, J.O., Lee, J.E., Park, Y.J., Nam, H.R., Park, W., Ahn, Y.C. and Huh, S.J. (2004) Patterns of Failure in Gastric Carcinoma after D2 Gastrectomy and Chemoradiotherapy: A Radiation Oncologist's View. British Journal of Cancer, 91, 11-17. http://dx.doi.org/10.1038/sj.bjc.6601896

[19] Kim, S., Lim, K.H., Lee, J., et al. (2005) An Observational Study Suggesting Clinical Benefit for Adjuvant Ostoperative Chemoradiation in a Population of over 500 Cases after Gastric Resection with D2 Nodal Dissection for Adenocarcinoma of the Stomach. International Journal of Radiation Oncology*Biology*Physics, 63, 1279-1285. 
http://dx.doi.org/10.1016/j.ijrobp.2005.05.005

[20] Yoo, C.H., Noh, S.H., Shin, D.W., et al. (2000) Recurrence Following Curative Resection for Gastric Carcinoma. British Journal of Surgery, 87, 236-242. http://dx.doi.org/10.1046/j.1365-2168.2000.01360.x

[21] Shimada, K. and Ajani, J.A. (1999) Adjuvant Therapy for Gastric Carcinoma Patients in the Past 15 Years: A Review of Western and Oriental Trials. Cancer, 86, 1657-1668. http://dx.doi.org/10.1002/(SICI)1097-0142(19991101)86:9<1657::AID-CNCR6>3.0.CO;2-J

[22] Park, S.H., Kim, D.Y., Heo, J.S., Lim, D.H., Park, C.K., Lee, K.W., Choi, S.H., Sohn, T.S., Kim, S., Noh, J.H., Kim, Y.I., Park, J.O., Kim, K., Kim, W.S., Jung, C.W., Im, Y.H., Lee, M.H., Park, K., Park, C.H. and Kang, W.K. (2003) Postoperative Chemoradiotherapy for Gastric Cancer. Annals of Oncology, 14, 1373-1377. http://dx.doi.org/10.1093/annonc/mdg366

[23] Kim, J.S., Kim, J.S., Cho, M.J., Yoon, W.H. and Song, K.S. (2006) Comparison of the Efficacy of Oral Capecitabine versus Bolus 5-FU in Preoperative Radiotherapy of Locally Advanced Rectal Cancer. Journal of Korean Medical Science, 21, 52-57. http://dx.doi.org/10.3346/jkms.2006.21.1.52 